\title{
A carbon assessment and design tool to assist in planning low carbon development
}

\author{
Colin Beattie \\ Curtin University Sustainability Policy (CUSP) Institute \\ Email: colbeattie@gmail.com
}

\begin{abstract}
To avert runaway climate change the agreed international aim is to keep greenhouse gas emissions to a maximum of $450 \mathrm{ppm}$ of $\mathrm{CO}_{2}$-e (carbon dioxide equivalents) in the atmosphere. Those countries that have ratified the Kyoto protocol have agreed on specific targets in terms of percentages, generally but not always, against a baseline, of $\mathrm{CO}_{2}$-e levels produced in 1990. Having agreed in principal to specific individual figures for each country, and a consensus on which processes and activities should be included in the accounting, then it is simply a case of doing the arithmetic and in 2012, when the reporting period ends, it will be clear where the successes and failures lie.
\end{abstract}

2010 was the year when the majority of the planet's population moved to cities, a trend that is likely to continue, and with cities being responsible for possibly as much as $70 \%$ of the world's emissions, it is clear that the built environment needs some close scrutiny now and in the future.

Buildings are, and have been for the last two decades, the focus of assessment programs and there is a vast array of tools that have been developed in the form of checklists or rating measures, but those that provide clearly defined metrics are not common. In an atmosphere where there is, arguably, an understanding of the importance of energy use and how it relates to greenhouse gas emissions (at a commercial level if not domestic) there is an increasing interest in how our buildings perform in this regard. This is acknowledged by policies like the mandatory disclosure of building performance, now being rolled out across Australia. There also seems to be an understanding that considering precincts or neighbourhoods is as important, if not more important than individual buildings, because it integrates how people move between and around the city. This is extremely important considering the impact of various modes of transport on the production of greenhouse gasses.

Recently, the availability of assessment tools for sustainable development such as BREEAM (Building Research Establishment Environmental Assessment Method) Communities and the LEED (Leadership in Energy and Environmental Design) Neighbourhood Development tool, seem to have grown exponentially. These tools take on a range of forms from simple checklists to detailed rating tools, but few focus on actual metrics, without which it is difficult to understand the true impact of what is being assessed. Climate change as an environmental issue is proving to be extremely difficult to address, particularly in Australia where, should we choose to believe the media, the science is still being questioned. However if we consider that what the science is telling us is true, we are faced with a challenge of numbers.

Decarbonising Cities and Regions (DCR) is an Australian Research Council linkage project that proposes to examine the greenhouse gas emissions (GHGe) of four land redevelopment case studies. The proposal includes a framework that outlines the sources of GHGe that will be examined for all of the case studies. The framework proposed covers: raw materials and building assemblies, construction emissions, operational emissions, private transport, the full water cycle and emissions from municipal waste. This framework is featured in a study of carbon assessment tools which identified the $C^{C A P}$ Precinct tool as the most comprehensive for urban development and redevelopment in accordance with the DCR framework

$C^{C A P}$ Precinct has been developed to provide a number of sustainability metrics for developments at all scales, the focus of this paper will be the GHGe that a development proposal is responsible for from operational energy consumption, GHGe associated with water (pumping) and direct emissions from transport options available. The tool also calculates affordability based on annual operating costs and capital costs for technology options applied to a development to reduce GHGe. This paper contains a detailed review of the Kinesis $C^{\text {CAP }}$ Precinct tool.

Keywords: $\quad$ Energy, Greenhouse Gas Emissions, urban design, land development 


\section{INTRODUCTION}

Globally there is a general consensus that Climate Change is anthropomorphic and in order to prevent runaway climate change global temperature increases of not more than 2 degrees greater than pre-industrial levels must be maintained. This translates to a figure of $450 \mathrm{ppm}$ (parts per million) of $\mathrm{CO}_{2}$-e emissions as a global target allowing those countries that are so inclined to tackle the issue, to work towards achieving the objective (Meehl et al., 2007; UNFCCC, 2008).

Although Australia has the NGERS Act (National Greenhouse Energy and Reporting) to account for GHGe, there won't be a mandatory policy implemented to address their production until July 2012. We rely on other initiatives such as the Renewable Energy Target, The Clean Energy Initiative and the Building Energy Efficiency Disclosure Act to encourage the reduction of GHGe. So all the accounting process does is allow for the monitoring of GHGe across various sectors. With Australia vying for the position of world leader in emissions per capita (WRI, 2011) and the majority of the population of the world now living in towns and cities, it is clear that the GHGe the built environment is responsible for is worthy of examination.

According to the Clinton Climate Initiative "cities consume over two-thirds of the world's energy and account for more than $70 \%$ of global CO2 emissions" (Clinton Climate Initiative, 2010) although that figure doesn't align with the IPCC figures which suggest 30 to 40\% (Satterthwaite, 2008). Satterthwaite demonstrates a number of reasons that can contribute to such a large deviation demonstrating along the way how some of the largest most densely populated cities can be the hardest to target in terms of reducing emissions, if they are located in impoverished countries. It's certainly worth noting that tackling climate change cannot be done by rolling out the same measures across both the developing and developed world.

\section{EXISTING APPROACHES}

\subsection{Assessment Tools for Buildings}

For individual buildings there is a national standard for assessing performance in terms of sustainability. The National Building Energy Rating Scheme (NABERS), includes a metric for GHGe, based on the amount for a particular year. With Commercial Building Disclosure being rolled out across the country (Australian Government, 2010), there is now a scheme that requires all commercial building owner/occupiers, when selling or leasing floor space, to produce a Building Energy Efficiency Certificate (known as a BEEC) that provides both energy use and GHGe metrics. For the residential sector, Queensland has already introduced a certificate for existing property that is released on to the market and there is ongoing discussion on the best approach for rolling out a certification scheme nationwide (Queensland Government, 2010).

Part $\mathbf{J}$ of the Building Codes attempts to reduce GHGe in new buildings (ABCB, 2011a, 2011b). There are currently three tools that conform to the Australian Building Codes Board for residential development, the best known being AccuRATE. This provides a means of measuring the performance of the building envelope and calculating the energy required for heating and cooling to meet particular comfort levels, and is weighted to account for different climate zones across Australia. The result is a rating in stars from 1 to 10 - currently the 2010 Building Codes require a minimum of 6 stars for single residential although the adoption of the code has been delayed in some states through lobbying from the building industry.

New South Wales Planning Department has a tool of their own which focuses on reducing GHGe and potable water consumption (NSW Department of Planning, 2002). The tool is works with metrics as opposed to ratings, or checklists, upon which so many other sustainable development tools rely. The Basix tool works on the basis of establishing a business as usual (BAU) baseline and setting specific targets based on percentage improvements against BAU. The target for both GHGe and Water consumption is $40 \%$ improvement over BAU. Feedback has shown that the reductions in water consumption for dwellings certified with Basix, has been within $1 \%$ of the target figure (NSW Department of Planning, 2010). GHGe figures have also been positive however a number of factors prevent precise comparisons with the benchmark figures. Actual occupancy rates, number of bedrooms, varying income levels and a general trending increase in electricity consumption all contribute to skewing of the figures.

\subsection{Assessment Tools for Urban Development}

There is little that addresses the assessment of development at a larger scale, although a number of tools have been launched recently. BREEAM Communities was introduced in the UK in June 2009 (BREEAM, 2009). As a sustainability tool for urban development this was the first of its kind, but in terms of providing a metric 
for GHGe, it is still lacking. The US-based LEED-ND (Neighbourhood Development) tool was launched in April 2010 (USGBC, 2011). So within a year of each other the two most internationally recognized thirdparty building sustainability certification schemes had extended their products to incorporate the idea of 'community'. Whether the tools can be used for accreditation internationally is questionable because the methodologies behind these tools were originally developed to be regionally specific. The diversity of architecture, culture, climate and resources across regions suggests that any international comparison would be difficult to achieve using a universal sustainable measure (Rivera, 2009). That is the difficulty with tools that provide a rating (BREEAM (Pass, Good, Very Good, Excellent and Outstanding) and LEED (Certified, Silver, Gold, Platinum)). Climate change as a specific sustainable challenge has the ability of crossing the potential international divide of comparable assessability because the focus is on a specific metric - the amount of greenhouse gasses (a number) that a development is directly responsible for. The challenge then becomes: how to improve on that number wherever it is generated in the world, and the solution would be based on what is possible in that particular locality. That is what needs to be addressed if runaway climate change is to be avoided.

\subsection{Assessment Tools for Urban Development in Australia}

In Australia the Green Building Council (GBCA) are close to releasing their Communities tool as a pilot, but it is not yet known if specific metrics will be covered in the assessment methodology.

In NSW Landcom invested in the development of a tool for land development that followed the basic principles of the Planning Department's Basix tool, in that it would determine a reference or baseline against which targets could be set. The team that developed the original Basix tool was commissioned to produce Precinx for Landcom and has since progressed to the development of a number of tools using the IP developed for the Precinx tool. The particular tool covered in this paper is the $\mathrm{C}^{\mathrm{CAP}}$ Precinct modelling tool developed by Kinesis and is discussed in detail in section 3.

\section{C CAP PRECINCT}

The $\mathrm{C}^{\mathrm{CAP}}$ Precinct tool is an iterative design tool that allows the user to define a development using some simple inputs with the opportunity to build upon the initial data and through an iterative design development process, tune the development to meet the goals set by the developer and the planning authority.

Input data can initially be kept very simple because the tool has a built in algorithm that will create a scenario based on the climate zone, non-developable area (including conservation areas and riparian zones) and developable area (non-residential, mixed use and residential). These aggregated figures are used to "reverseengineer" a reference model. For non-residential and mixed use areas a proportion of the area is assigned to playing fields, public gardens, native parklands and public plazas, all of which have an assumed permeability - a key requirement of the water module. Road requirements are split into major roads; collector, local and minor streets; and laneways, and are assigned for all three developable areas. This then leaves three areas which are broken down once more so that they match the original developable areas keyed in at the start of the exercise. These areas control the size of the footprint of the buildings that can be constructed. The mixed use inputs area of the tool also asks for the average number of storeys above the non-residential uses that are allowable, assuming mixed use forms part of the development. In the residential input area of the tool areas are set aside for parks and public plazas leaving the balance to be used for the actual dwellings. The dwelling mix is then controlled through the selection of a number of apartment types from a pre-defined list which also includes gross floor areas, total number of bedrooms and total number of storeys allowable. The numbers of single and attached dwellings are calculated in a similar way, from another pre-defined list of 'typical' dwellings.

A figure now exists for all of these parameters which are held by the tool in the reference model. As a layout is developed the areas assigned by the tool in the reference model, can be individually overridden by the figures from the proposed development plan. The tool now holds two models, the reference model is retained as a 'control' and the proposed development model which now has something to be measured against.

Now that the relevant data needed for the model calculations have been identified, the tool can then define the performance of the proposed development by measuring five key performance indicators: land use and transport; embodied emissions; energy and greenhouse gas; water; and affordability. The figures shown in this paper are from a Western Australian case study which was modeled by Kinesis as part of a sustainability 
analysis for a mixed use development site with nearly 5,000 new dwellings and over 100,000 sq.m. of commercial floor space.

\subsection{Land Use and Transport}

This module calculates the vehicle hours travelled (VHT) and related GHGe by the precinct residents. The VHT figure includes the time spent driving to work, leisure, and to access goods and services.

There are two key elements to this part of the tool. The first is a vehicle kilometres travelled (VKT) regression model for Sydney that was originally developed by the NSW Department of Planning (Corpuz et al., 2006). Fifteen predictor variables are included in the final recommended model which has a good $\mathrm{R}$ square value of 0.731. Combined with the NSW Household Travel Survey, a travel profile for the average person living in an area is created. VHT applies to private motor vehicle use and is considered a social measure although research that corroborates this view has not been found. It can be argued however, that a lower VHT per person figure would reflect better social amenity and/or

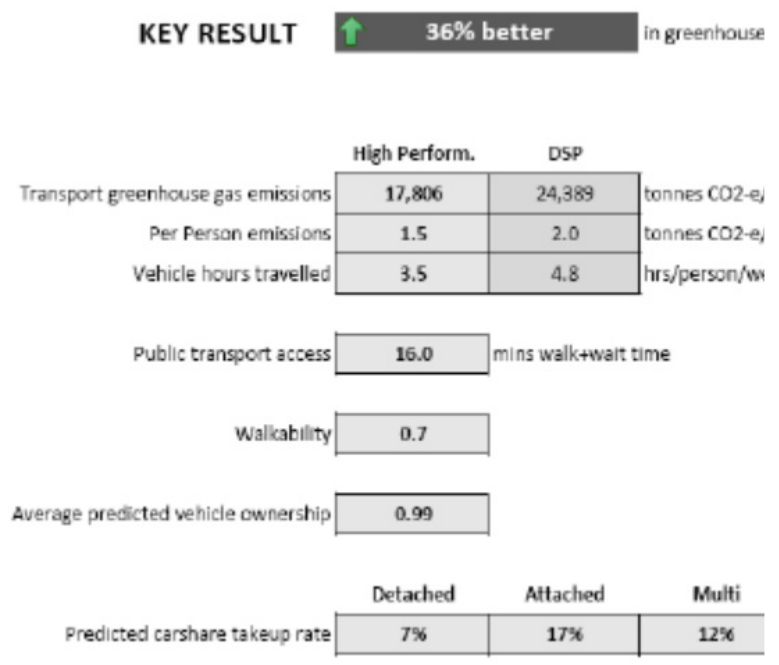

Figure 1. An example of the transport results from a Western Australian case study employment opportunities within easy reach - by foot, bicycle or public transport perhaps. Of more relevance to this research is the GHGe which are determined using the same data set but also considers the effect of efficient public transport included in the design. Variables such as walk/wait times are critical if the aim is to reduce reliance on private motor vehicles. This becomes a powerful means of testing development designs and maximising the capacity and importantly, the potential uptake of good public transport.

The second key element is the Walkscore or walkabilty index (Walkscore, 2011). Walkscore is a system of assessing a location based on the distance in 0.25 mile increments to local amenities in a group of nine weighted categories including: grocery stores, restaurants, banks, parks and schools to name but a few. This is a critical variable in informing the modeling discussed above.

The ability to adjust the frequency and walk/wait times for different public transport types, together with options to select different levels of parking (both on and off road provisions), will clearly be influential on car ownership.

\subsection{Energy and Greenhouse Gas}

The energy module is designed to calculate the electricity and gas energy demands and thus, the GHGe of a development proposal. This is managed through the assembly of a ledger of all the residential and non-residential loads. In addition the ledger assigns thermal loads based on water heating, space heating and space cooling demands. The ledger is based on half-hourly increments taken over the year. By comparing actual demands provided by utility companies and data from the Bureau of Meteorology (BOM) and the Australian Bureau of Statistics (ABS) it is possible to see the correlation of actual energy use against the data from the ABS which provides a percentage breakdown of uses in the home i.e. lighting, clothes washing and drying, dishwasher use, refrigeration, space heating and cooling, and hot water. Predicted energy use can then be reconciled against actual energy use. Once the ledger has

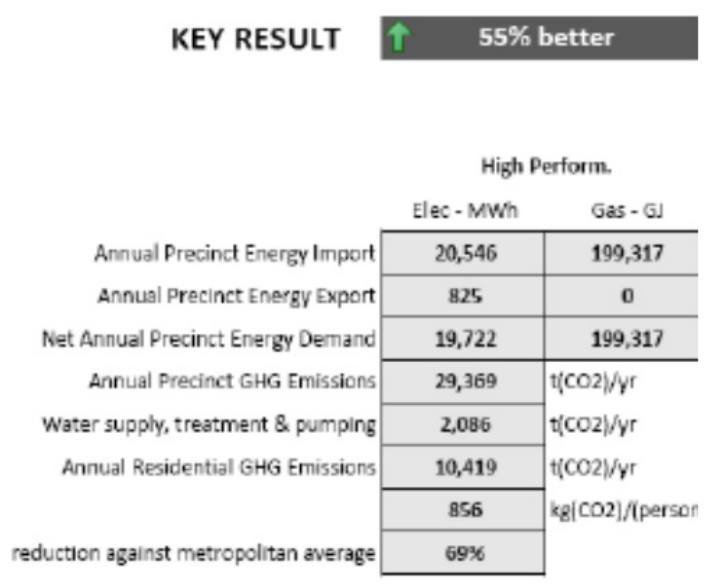

Figure 2. Energy and Greenhouse Gas results from the same model as above 
itemised the activities and the energy use is assigned to each of these, it is possible to consider a range of scenarios designed to improve energy efficiency. As the tool is meant to be used in an iterative design process it is possible to consider a range of strategies to determine the most effective approach for a particular dwelling mix as well as where the greatest cost benefit lies. This is important because different building forms will need different approaches to reducing energy. For example a proposal consisting primarily of multi-unit dwellings will have limited scope for solar technologies (photovoltaic and solar hot water) due to limited roof area, particularly for multi-storey buildings. However alternative technologies such as cogeneration could prove extremely effective in such developments.

\subsection{Embodied Emissions}

The Embodied emissions module accounts for the one-off release of greenhouse gasses in the mineral extraction, manufacture, transport and assembly of materials for the residential component of a proposed development. The lifecycle inventory database used for calculating these impacts is derived from the SimaPro LCA Software package.

A list of typical building assemblies which make up the overall construction of a dwelling is used to create a list of materials for each of the three dwelling types (detached, attached and multi-unit). Each assembly has a dropdown list of options for that particular assembly from which to choose. A further level of detail is added which allows the user to choose the origin of fourteen of the most commonly used building materials which is then applied to that particular material across the entire development. The embodied emissions are considered as a one-off calculation and, in terms of a practical approach to gain an order of magnitude, this will provide a reasonable figure for consideration. In reality a multitude of contractors will be involved in the construction of a master plan over a significant period of time and each will follow their own procurement plan, involving their own preferred sub-contractors and suppliers making it unrealistic to model a reflection of what will actually be constructed.

Mixed use, commercial and retail buildings are not considered, the reason given is that commercial building designs vary so dramatically. Perhaps the impact of embodied emissions is relatively small. A view supported by the United Nations Environment Program (UNEP), Sustainable Buildings and Climate Initiative (SBCI) who do not consider embodied emissions to represent a large portion of the total life cycle emissions (UNEP - SBCI, 2009), in their work to determine a common carbon metric. They suggest that only $10-20 \%$ of emissions produced fall outside of the "Use Phase" of a building, which is then split between start and end of life processes. Studies undertaken in the UK show that the ratio of operational to embodied emissions which was previously considered as being 80:20 is moving closer to 60:40 (Lane, 2007). In addition different building types will have different ratios for example the fabric of a warehouse could have as much as $60 \%$ of the total lifetime emissions of the building (Sturgis \& Roberts, 2010). As operational emissions are reigned in embodied emissions will undoubtedly account for an increasing proportion of the emissions a development is responsible for. This being the case, the tool needs to be able to consider at least a (notional) figure for commercial embodied emissions.

\subsection{Water}

The Water module works similarly to the Energy and Greenhouse Gas module in that a ledger is created containing an hourly account of demands and supplies measured against the reference model using data from the Water Corporation. Non-residential water use is also covered by the same data set. The hourly modeling can demonstrate periods of high water use (e.g. from irrigation or heat rejection) and reconcile these with appropriate alternative supplies.

Among the options that can be tested are outcomes based on different sizes of rainwater tanks in private residences and importantly, various options on where this water can be used including irrigation, toilet flushing and laundry use. The potential for the tool to provide a compelling argument for extending the opportunities for rainwater recycling is obvious. It will be interesting to see how this develops in areas where policy barriers exist restricting the use of recycled water.

The importance of the linkages between the modules is clearly demonstrated by a figure showing the volume of water required for heat rejection purposes in a cogen plant (if considered in the onsite energy module). This will appear as a consumption figure with options provided for sourcing the cooling water required.

The results from this module identify the impact that the development has on flow rates based on the reference model data set and has the ability of demonstrating the impact of some common water treatment scenarios. 


\subsection{Cost and Affordability}

The Cost and Affordability module assesses total housing costs and the capital and recurrent costs of the proposed green infrastructure, such as the marginal costs of installing rainwater tanks or a cogeneration plant. It also allows the impact of government policies and incentives to be assessed, such as a solar feed-in tariff.

The culmination of these inputs provides a picture of the total affordability of the precinct. The energy and water consumption of

GREEN INFRASTRUCTURE CAPITAL COSTS

\begin{tabular}{|c|c|c|c|}
\hline Energy & High Perform. & DSP & \\
\hline NatHERS upgrade from 5 -star & $\$ 13,696,520$ & $\$ 13,696,520$ & \\
\hline Solar hot water net cost & $\$ 4,466,145$ & $\$ 14,406,920$ & (with RECs + subsidy \\
\hline Solar PV (private) & $\$ 5,045,436$ & so & (with RECs] \\
\hline Solar PV (community) & \$o & \$̦ & \\
\hline Cogeneration & $\$ 6,658,500$ & so & \\
\hline
\end{tabular}

\begin{tabular}{rl|c|}
\multicolumn{1}{c}{ Water } & \\
\cline { 3 - 3 } Raintanks & $\$ 0$ & $\$ 0$ \\
\cline { 2 - 3 } Recycled water scheme & $\$ 3,720,589$ & $\$ 0$ \\
\cline { 2 - 3 } & &
\end{tabular}

Figure 3. Green Infrastructure capital costs associated with the development (4850 dwellings) the dwellings is reported as energy and water bills (or income with exported electricity), and vehicle kilometres travelled and car ownership is reported as the costs associated with travel and running a vehicle.

Finally, the marginal abatement costs of the sustainability design strategies entered by the user can be compared against each other to ensure the best performance can be achieved for the lowest marginal cost. In this example the key changes between the District Structure Plan and the High Performance case are:

- Transport - Upgraded from bus to light rail, a reduction in parking provision and the introduction of a car share scheme;

- Embodied CO2 - Incorporation of a recycled component to the concrete component of construction;

- Energy - Introduction of a 1,500kWe cogeneration plant servicing high density resi and commercial with hot water, heating and cooling;

- Water - Improved fixture and appliance efficiency and the introduction of third pipe recycled water supply.

The additional capital cost per dwelling is calculated at $\$ 5,600$ which is less than $\$ 1,000$ more expensive than that proposed in the District Structure Plan case, for significantly greater benefits across all five KPI's as demonstrated in Figure 4.

District Structure Plan case:

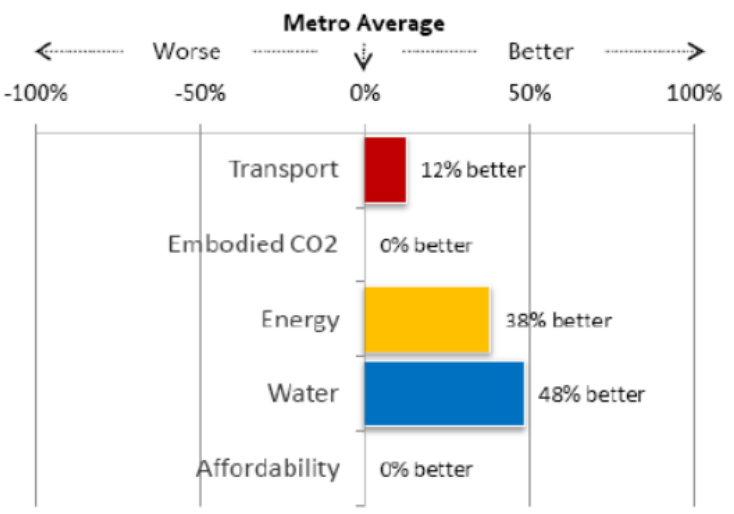

\section{High Performance case:}

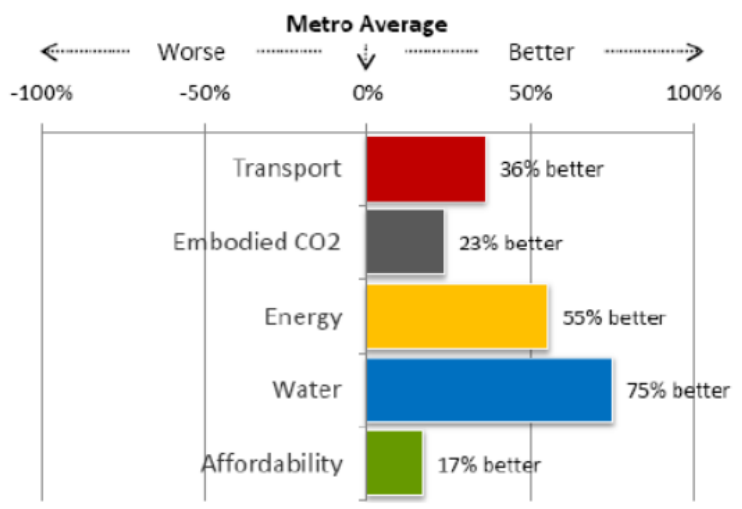

Figure 4. The summary section showing the KPI results, generated automatically through the Excel workbook that forms the user interface of the tool

In forming a summary, the report provides percentage changes in the KPI's against a reference model. This is normally the metropolitan average but can be set to any benchmark that the developer wishes to use.

\section{CONCLUSION}

When creating a District Structure Plan, a land-use strategy which could include a GHGe target, needs to be designed. Land-use zoning determines the maximum developable area from which a figure for GHGe can be calculated using generic building models. As a development matures an increasing number of stakeholders 
such as professional developers add another level of detail following the initial district planning framework. The model can accommodate this additional detail which enhances the final data produced. Here is where the author determines a potential loss of cohesion in the model's management. The Planning Authority, in theory, having accepted a master plan, have control of the model and set the benchmarks for the developers to meet within the master plan boundary. When ownership is broken down into smaller building lots, there is the question of who is responsible for maintaining the model. It is recommended that a management plan for this stage of the development process is stated at the outset. Two options that could be considered are: the developer invests in the tool and uses it to develop a detailed model that can then be connected into the overall Master Plan. Alternatively, the Planning Authority could provide the developer the service of modelling their development proposal. Both options will allow the data to be recalculated to ensure the overall development targets are within a specified tolerance. As the tool has only started rolling out in NSW and WA, little data is available to track this stage of model usage.

Enabling tools such as $\mathrm{C}^{\mathrm{CAP}}$ Precinct for local environmental planners and policy officers could provide the mechanism for realising the carbon reduction aspirations of our cities.

\section{ACKNOWLEDGEMENTS}

The author acknowledges Curtin University, the Australian Research Council and AHURI in supporting this work. Thanks also go to David Holden of Kinesis for assisting me in developing an understanding of the $\mathrm{C}^{\mathrm{CAP}}$ suite of tools.

\section{REFERENCES}

BCA 2011. Building Codes of Australia. Class 1 and Class 10 Buildings. Housing Provisions. VOLUME TWO, (2011a).

BCA 2011. Building Codes of Australia. Class 2 to Class 9 Buildings. VOLUME ONE, (2011b).

Australian Government. (2010). Commercial Building Disclosure. A National Energy efficiency Program. Retrieved 6 October, 2011, from http://www.cbd.gov.au/default.aspx

BREEAM. (2009). BREEAM Communities. Retrieved 6th October, 2011, from http://www.breeam.org/

Clinton Climate Initiative. (2010). C40 Cities Climate Leadership Group. Retrieved 4th July, 2011, from http://www.c40cities.org/

Corpuz, G., McCabe, M., Ryszawa, K., Transport and Population Data Centre, \& New South Wales Department of Planning. (2006). The Development of a Sydney VKT Regression Model. Paper presented at the 29th Australasian Transport Research Forum.

Lane, T. (2007). Our Dark Materials. Building Magazine(45).

Meehl, G. A., Stocker, T. F., Collins, W. D., Friedlingstein, P., Gaye, A. T., Gregory, J. M., et al. (2007). Global Climate Projections. In S. Solomon, D. Qin, M. Manning, Z. Chen, M. Marquis, K. B. Averyt, M. Tignor \& H. L. Miller (Eds.), Climate Change 2007: The Physical Science Basis. Contribution of Working Group 1 to the Fourth Assessment Report of the Intergovernmental Panel on Climate Change. Cambridge: Cambridge University Press.

NSW Department of Planning. (2002). BASIX - Building Sustainability Index. Retrieved 22/3/10, from http://www.basix.nsw.gov.au/

NSW Department of Planning. (2010). BASIX Performance Monitoring. Retrieved. from.

Queensland Government. (2010). National Residential Mandatory Disclosure. Retrieved 6th October, 2011, from http://www.dlgp.qld.gov.au/sustainable-housing/

Rivera, A. (2009). International Applications of Building Certification Methods: A Comparison of BREEAM and LEED. Paper presented at the 26th Conference on Passive and Low Energy Architecture.

Satterthwaite, D. (2008). Cities' contribution to global warming: notes on the allocation of greenhouse gas emissions. Environment \& Urbanization, 20(2).

Sturgis, S., \& Roberts, G. (2010). Redefining Zero: Carbon Profiling as a solution to whole life carbon emission measurement in buildings. London: Royal Institute of Chartered Surveyors.

U.S. Green Building Council. (2011). LEED for Neighbourhood Development. Retrieved 6th October, 2011, from http://www.usgbc.org/DisplayPage.aspx?CMSPageID=148

UNEP - SBCI. (2009). COMMON CARBON METRIC for Measuring Energy Use \& Reporting Greenhouse Gas Emissions from Building Operations.

UNFCCC. (2008). Kyoto Protocol Reference Manual on Accounting of Emissions and Assigned Amount. Bonn.

Walkscore. (2011). Walkscore Methodology. Retrieved 3 August, 2011, from http://www.walkscore.com/

World Resource Institute. (2011). CAIT-UNFCCC > Yearly Emissions 2008. Climate Analysis Indicators Tool Retrieved 4th July, 2011, from http://cait.wri.org/cait.php 